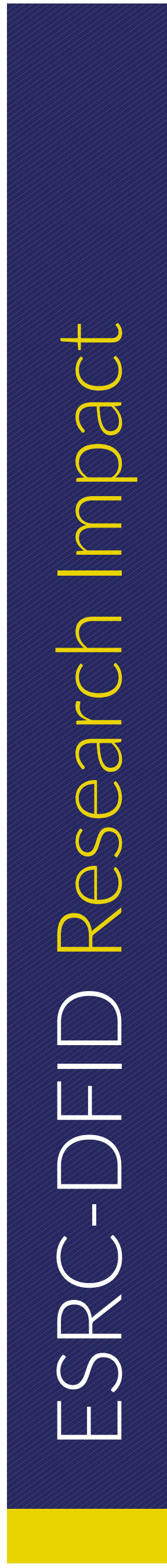

\title{
REDUCING TEENAGE PREGNANCY IN SIERRA LEONE
}

Research directly involving teenagers and their families in Sierra Leone to reduce teenage pregnancy has helped pave the way for a new community-friendly Child and Family Welfare Policy. The research by the Columbia Group for Children in Adversity and UNICEF Sierra Leone mobilised local people through child- and youth-led education initiatives and through closer connections with district health workers. Thanks to the project, condom use increased, teenage girls reported feeling more confident to say 'no' and boys showed more willingness to act responsibly. The findings directly influenced the Sierra Leone government's development of a new policy on child protection.

\section{THE CHALLENGE}

Sub-Saharan Africa has the world's highest teenage pregnancy rates, with one in five girls aged 15 to 19 giving birth. ${ }^{1}$ Many girls who become pregnant are forced to leave school. Complications during pregnancy are common and many girls undergo unsafe abortions. Babies born to adolescent mothers face a substantially higher risk of dying. ${ }^{2}$ In 2013 , with Sierra Leone recording a 68 per cent pregnancy rate among adolescent girls (with a mean age of 15), ${ }^{3}$ the president declared that the problem demanded urgent action and launched a national strategy to address it. ${ }^{4}$

A global review of community-based child protection mechanisms, such as Child Welfare Committees, found that these often failed to protect vulnerable children from dangers like teenage pregnancy and early marriage. Problems included a lack of local ownership deterring families from getting involved, committees collapsing once funding had ceased and poor collaboration between community efforts and district-level health workers. This highlighted a need for a more communityled approach to child protection in places like Sierra Leone, to stem the high rates of teenage pregnancy and prevent the harm it causes to girls' health, their futures and to economic and social development.

\section{THE RESEARCH}

In 2012 the action research team began working in two districts in Sierra Leone: Moyamba District within the Mende-speaking southern area and Bombali District within the predominantly Temne-speaking

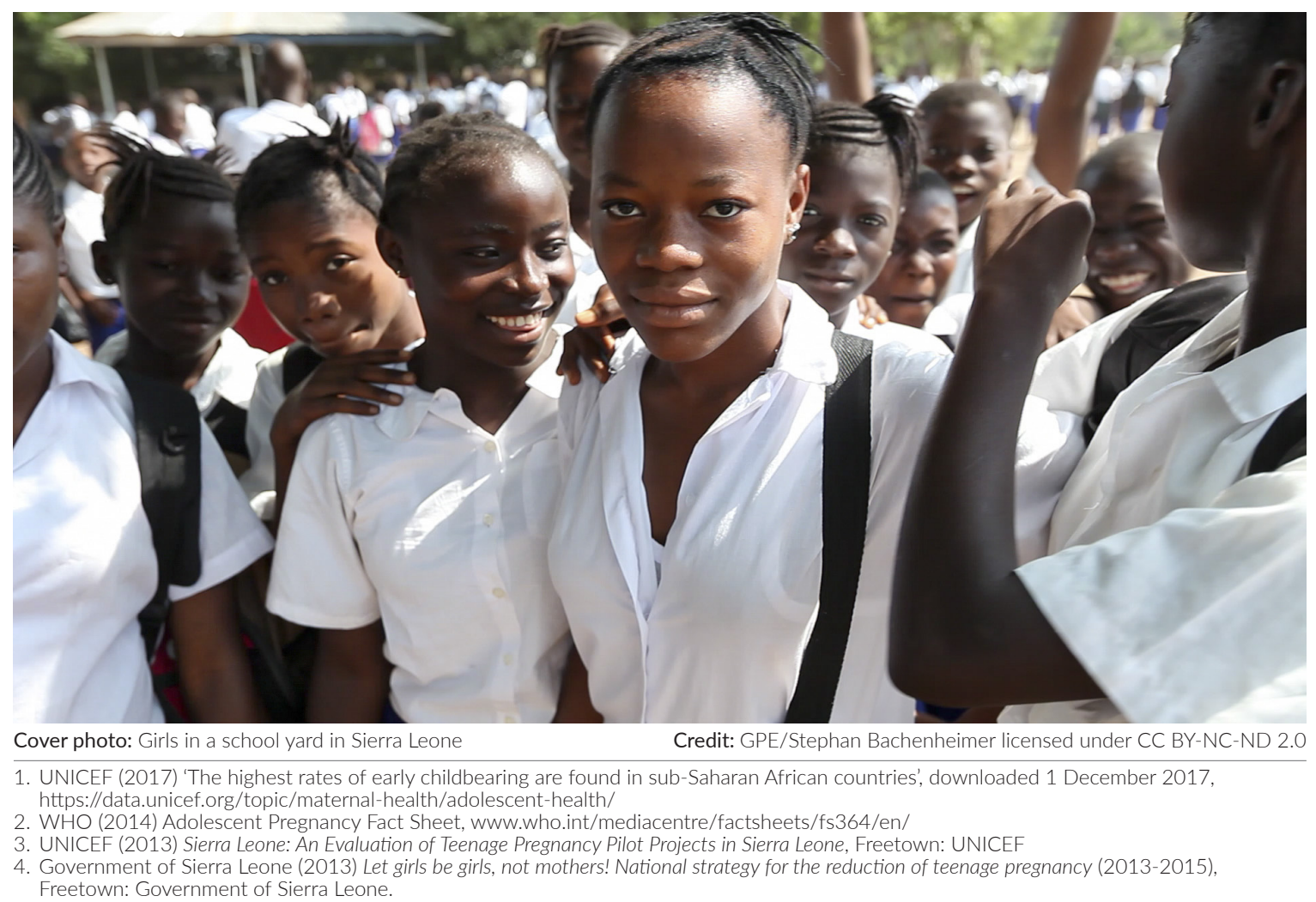


northern area. After extended dialogue, community members chose to address teenage pregnancy through family planning, sexual and reproductive health education and life skills. Communities encouraged families to collaborate with the district government, health services and schools. The team coordinated training by NGOs and the provision of contraceptives and education around puberty, sexuality, pregnancy and pregnancy prevention by the District Ministry of Health. Communities organised role plays among teenage girls and boys while parents and children had candid discussions about puberty, sex and preventing pregnancy. From the outset, the research team worked closely with UNICEF, which played a lead role in child protection. UNICEF engaged with Sierra Leone's national Child Protection Committee and the Ministry of Social Welfare, Gender and Children's Affairs, which helped to select the areas for study.

\section{THE IMPACT}

A mid-point project evaluation in July 2014 showed that teenagers reported ${ }^{5}$ a greater intent to use condoms while teenage girls reported feeling empowered to refuse unwanted sex more frequently. Both girls and boys said that they had learned how to discuss and negotiate with their partners about sex, and how to plan their sexual activities in light of wider life goals. Boys openly acknowledged their responsibility to prevent teenage pregnancy contrasting sharply with their previous behaviour.

\section{D}

The insights gave us the evidence we needed to work with the government on a radical shift in child protection policy.

David Lamin, UNICEF

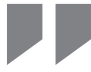

Health workers, teenagers and their families indicated seeing a significant decrease in teenage pregnancies. Prior to the research, in an average school year there were five or six teenage pregnancies per village in both districts. In the 2013/14 school year, half the communities reported no new teenage pregnancies, and the other half reported only one new teenage pregnancy. Some villages had spontaneously begun to discuss the problem of early marriage.

Although the Ebola crisis disrupted the project in August 2014, the action research did significantly influence national policy on supporting vulnerable children in Sierra Leone - in particular the findings that local people relied on community-owned processes and existing family and community mechanisms. This directly influenced Sierra Leone's government and UNICEF to collaborate on a new policy placing familyand child-led action at the centre of child protection. The new Child and Family Welfare Policy enacted in 2015 embodied insights from the research.

David Lamin ${ }^{6}$ of UNICEF Sierra Leone explained the value of the research: 'The insights into teenage pregnancy and the need for communities themselves to drive efforts to protect children provided us with the evidence we needed to work with the government on a radical shift in child protection policy.' He said the findings were being used to develop ways to implement the policy, adding: 'there are now plans to share this evidence and approach with the governments of Ivory Coast, Liberia and Guinea.

\section{FURTHER READING}

Stark, L.; Tan, T.; Muldoon, K.A.; King, D.; Lamin, D.; Lilley, S. and Wessells, M.G. (2015) 'Family structure and sexual and reproductive health outcomes among adolescents in rural Sierra Leone', Global Public Health 11.3 www.tandfonline.com/doi/full/10.1080/174416 $\underline{92.2015 .1031155}$

Stark, L.; Macfarlane, M.; King, D.; Lamin, D.; Lillley, S. and Wessells, M. (2014) A community-driven approach to reducing teenage pregnancy in Sierra Leone: Midline Evaluation, London: Save the Children

Wessells, M.G. (2015) 'Bottom-up approaches to strengthening child protection systems: Placing children, families, and communities at the center', Child Abuse and Neglect: The International Journal 43: 8-21

Wessells, M.G.; Lamin, D.; King, D.; Kostelny, K.; and Lilley, S. (2015) 'The limits of top-down approaches to managing diversity: lessons from the case of child protection and child rights in Sierra Leone', Peace and Conflict: Journal of Peace Psychology 21.4: 574-88

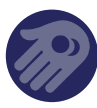

Inter-Agency Research On Strengthening CommunityBased Child Protection For Vulnerable Children In

\section{Sierra Leone}

This research was funded by the ESRC-DFID Joint Fund for Poverty Alleviation. It was conceptualised by the Inter-Agency Learning Initiative on Strengthening Community-Based Child Protection Mechanisms, which is coordinated by Save the Children. The research team was led by Principal Investigator Michael Wessells, Columbia University, in collaboration with UNICEF, United States.

5. Stark, L. et al. (2014) A community-driven approach to reducing teenage pregnancy in Sierra Leone: Midline Evaluation, London: Save the Children; Wessells, M.G. (2015) 'Bottom-up approaches to strengthening child protection systems: Placing children, families, and communities at the center', Child Abuse and Neglect: The International Journal 43: 8-21.

6. Extracts from an audio recorded interview between M. Wessells and D. Lamin, June 2014.

\section{THE IMPACT INITIATIVE}

\section{For International Development Research}

The Impact Initiative seeks to connect policymakers and practitioners with the world-class social science research supported by the ESRC-DFID Strategic Partnership, maximising the uptake and impact of research from: (i) the Joint Fund for Poverty Alleviation Research, and (ii) the Raising Learning Outcomes in Education Systems Programme. We seek to identify synergies between these programmes and their grant holders, support them to exploit influencing and engagement opportunities, and facilitate mutual learning. The Impact Initiative is a collaboration between the Institute of Development Studies (IDS) and the University of Cambridge's Research for Equitable Access and Learning (REAL) Centre.

\section{CREDITS}

This impact story was written by James Georgalakis, the Institute of Development Studies (IDS), in collaboration with Professor Michael Wessells, Columbia University.

$\triangle$ info@theimpactinitiative.net \#ww.theimpactinitiative.net @the_Impact_Init \#impactlessons

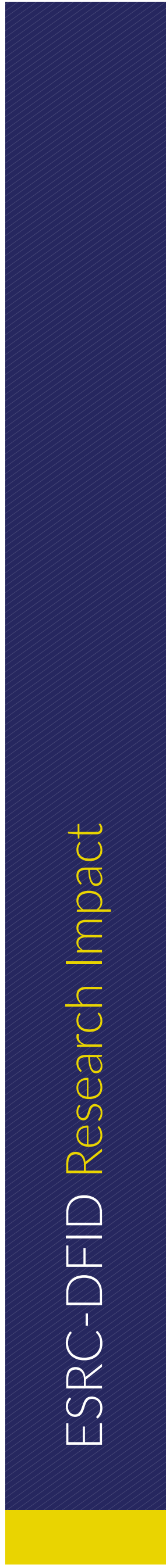

